\title{
Reporting nuclear cardiology studies: Is the cup half-full or half-empty?
}

\author{
Neha Yadav, MD, ${ }^{a}$ and Rami Doukky, MD, MSc, FASNC ${ }^{\mathrm{a}, \mathrm{b}}$ \\ a Division of Cardiology, John H. Stroger, Jr. Hospital of Cook County, Chicago, IL \\ b Division of Cardiology, Rush University Medical Center, Chicago, IL
}

Received Nov 25, 2016; accepted Nov 27, 2016

doi: 10.1007/s12350-016-0748-0

\section{See related article, pp. 986-994.}

In this issue of the journal, Maddux et al. present their findings on improved compliance with reporting guidelines in U.S. nuclear cardiology laboratories seeking accreditation from the Intersocietal Accreditation Commission (IAC). ${ }^{1}$ The nuclear cardiology report is studded with a wealth of clinical, exercise, safety, physiologic, hemodynamic, electrocardiographic, and perfusion data that not only yield diagnostic and prognostic implications, but also guide decision-making. For the past 15 years, the American Society of Nuclear Cardiology (ASNC) has spearheaded the movement to elevate the nuclear cardiology report to a standardized, all-encompassing document that contains essential elements needed for timely clinical decision-making. ${ }^{2-6}$ The 2009 ASNC standardized reporting guidelines serve as a framework for accreditation agencies to establish reporting standards for nuclear laboratories seeking accreditation. ${ }^{6,7}$ Over the past decade, physician-leaders, inter-disciplinary societies as well as healthcare organizations have spent considerable energy and resources to educate care teams and laboratories on best practices in nuclear cardiology, including "habit-building" exercises in issuing comprehensive, intelligible clinical reports.

Tilkemeier et al. reported a high degree of noncompliance with the IAC standards among nuclear cardiology laboratories applying for accreditation in $2008 .{ }^{8}$

Reprint requests: Rami Doukky, MD, MSc, FASNC, Division of Cardiology, John H. Stroger, Jr. Hospital of Cook County, 1901 W. Harrison St., Suite \# 3620, Chicago, IL 60612; rami_doukky@rush.edu J Nucl Cardiol 2018;25:995-8.

$1071-3581 / \$ 34.00$

Copyright (c) 2016 American Society of Nuclear Cardiology.
They also determined that feedback from prior accreditation applications improves compliance with reporting standards on subsequent reaccreditation cycles. ${ }^{8}$ In this study, Maddux et al. retrospectively compared adherence to reporting guidelines between the years 2008 and 2014 among over 1800 laboratories that applied for IAC accreditation or reaccreditation in those calendar years.

\section{ELEMENTS OF THE REPORT}

The authors demonstrated that the proportion of fully compliant reports has risen from $35 \%$ in 2008 to $57 \%$ in 2014. Importantly, the proportion of reports with high severity deficiencies, such as defect quantification, wall motion analysis, and timeliness, has fallen from $40.4 \%$ to $30.4 \%$. While these are significant improvements, we have to ask ourselves: Is it good enough? Is the cup half-full or half-empty? Is $0 \%$ deficiency, especially in high importance elements, achievable?

On the surface, compliance with the timeliness benchmark appeared to have worsened from $7.2 \%$ in 2008 to $10.7 \%$ in 2014 . However, this is likely due to tightening of the reporting timeliness standard from 4 days in 2008 to 2 days in 2014. Yet, we should strive for a timely report in $100 \%$ of cases.

One cause for concern is that perfusion defect quantification (size, severity, reversibility, location) did not show any improvement and remained among the most non-compliant elements in 2014 (21.1\%). In the era of value-conscious healthcare and outcome-driven management, defect quantification is paramount for evidence-based decision-making. A wealth of observational studies has demonstrated that defect quantification not only provides valuable diagnostic and prognostic information, but can also guide management strategy and identify coronary revascularization targets. ${ }^{9,10}$ Thus, a report that lacks complete defect quantification undermines the diagnostic and prognostic information gained by myocardial perfusion imaging, compromising its value in decision-making. 


\section{LABORATORY CHARACTERISTICS}

The study by Maddux et al. also examined the characteristics of nuclear cardiology laboratories applying for accreditation.

\section{Hospital vs Non-hospital Laboratories}

The significant increase in the percentage of hospitals seeking accreditation [61 (6.2\%) in 2008 to 91 (10.9\%) in 2014] is noteworthy. Hospital-based laboratories are exempt from accreditation by third party payers, including Centers for Medicare and Medicaid (CMS), while accreditation is mandated for independent testing facilities and physician offices. The fact that more hospitals are applying for accreditation may indicate that hospitals are recognizing the value of laboratory accreditation. Unfortunately, this report may not tell the full story in respect to hospital-based laboratories, as many hospitals seek accreditation from different accreditation bodies (the American College of Radiology and The Joint Commission). Another important observation is that, in 2014, hospital reports had significantly fewer deficiencies compared to those of non-hospitals (mean 0.8 vs. 1.3 deficiency, respectively). Hospitals are making better strides toward full adherence, perhaps due to greater availability of structured reporting software and quality improvement initiatives.

\section{Certification Board of Nuclear Cardiology (CBNC)}

There was an increase in the number of CBNCcertified physicians per laboratory. This may be due to increased recognition of the value of CBNC status as a testament of physician excellence and an avenue to acquire radionuclides authorized user licenses. While CBNC-certified physicians better adhered to reporting standards than non-certified physicians in 2008, there was no difference in compliance in 2014. It appears that the accreditation process may have eliminated differences in compliance related to physicians' credentials, motivating all physicians to improve their compliance, irrespective of their CBNC status.

\section{Regional Differences}

It is worth noting that the significant geographic regional variations in compliance seen in 2008 appear to have dissipated in 2014; this may be a direct effect of standardization mandated by IAC. The U.S. health system is plagued by regional variations in adherance to practice standards. This report demonstrates that standardization and accreditation processes can help overcome differences in adherence to standards of care across regions.

\section{Accreditation Cycle}

Notably, $79.0 \%$ of facilities applied for accreditation the first time in 2008, compared to only $5.7 \%$ in 2014. Thus, most laboratories were familiar with the accreditation requirements in 2014, which explains the observed improvement in compliance. There was also a significant increase in the percentage of facilities granted accreditation at initial application in 2014 compared to 2008 (37.4\% vs $13.9 \%$, respectively). This observation is likely a reflection of increasing awareness and knowledge of accreditation metrics, permitting laboratories to get accredited on their first attempt. Active dissemination of transparent accreditation standards, educational seminars/webinars, and sharing of intelligence between laboratories have helped in developing the "know how" of the accreditation process.

\section{FUTURE CHALLENGES OF THE NUCLEAR CARDIOLOGY REPORT}

\section{From Habit Building to Hard Wiring}

Providing high-quality medical care and satisfying all guidelines and regulatory requirements is more complex than ever. Despite progress in nuclear cardiology reporting, we have a lot of ground to cover. An ASNC workgroup is actively engaged in writing new comprehensive reporting guidelines for all nuclear cardiology studies. It is expected that the bar will be reset a bit higher, presenting new challenges in satisfying future reporting guidelines. Building new habits to satisfy toughening reporting requirements by education alone is rather difficult; we will always play "catchup." Technology can provide solutions. Using structured reporting software with hard-wired, guidelinedriven reporting standards as well as built-in reminders and hard-stops for high importance reporting elements would ensure a complete and informative report every single time. These software packages can be fitted with decision support tools to provide individualized prognostic data using a wealth of information from nuclear cardiology literature. In the near future, advanced machine learning applications will allow us to integrate clinical, electrocardiography, exercise, hemodynamic, defect quantification, and other ancillary imaging data to provide a patient-specific estimation of risk, aiding in individualized decision-making in a way the human brain cannot do. ${ }^{11,12}$ Moreover, structured reporting applications can also aid in conducting quality improvement efforts, such as tracking radiation dose and 
handling of critical findings. Structured reporting software is abundant but costly, thus not widely available outside of large healthcare organizations. ASNC should focus on enhancing the availability and affordability of high-quality structured reporting and decision support tools to take nuclear cardiology reporting to the next level of patient-centered care.

\section{Unified Stress and Perfusion Imaging Report}

The present study could not provide data on the proportion of laboratories that have combined stress and imaging reports. The full integration of stress and perfusion data in a single report is often hindered by logistic and financial boundaries and turf battles. Current technology in structured reporting software permits two signatures by a cardiologist (stress portion) and an imaging specialist (nuclear portion). However, financial and billing constraints may prevent a double signature. These limitations can be overcome by a close collaboration between cardiology, radiology, nuclear medicine, billing, and information technology departments.

\section{Appropriate Use Reporting}

Appropriate use of myocardial perfusion imaging improves the acumen of risk stratification and reduces radiation risk, while improving the value of perfusion imaging studies. ${ }^{13-15}$ The imaging community will soon be forced to address the issue of documenting adherence to appropriate use criteria (AUC) in the nuclear cardiology report. CMS is in the process of implementing the Protecting Access to Medicare Act (PAMA). This legislation will require the ordering physician to consult AUC using a CMS-approved, computer-based decision support tool when ordering advanced imaging, including myocardial perfusion studies. The imaging specialists will not be paid for their services if they do not have documentation that the ordering physician consulted an AUC decision support tool. As a result, there will be a massive shift, wherein the burden of reducing inappropriate use will move largely from payers to providers. ${ }^{16}$ Again, technology solutions can ameliorate this burden. Deep integration of decision support tools in the electronic order entry systems can provide seamless, real-time guidance on study appropriateness with minimal provider burden. These AUC data can seamlessly flow into the clinical report. High-level engagement of all stakeholders will be critical to fully realize these goals.

\section{Registries}

Accreditation bodies provide cyclic assessment of a sample of nuclear cardiology reports. Between accreditation cycles, it is easy for providers and laboratories to slip back into old habits. The ASNC ImageGuide ${ }^{\mathrm{TM}}$ registry continuously tracks and publicly reports, in realtime, indicators of excellence in radionuclide imaging, including crucial reporting measures. ${ }^{17}$ High performing registry participants can enjoy CMS reimbursement incentives for providing high-quality care. Again, technology permits full integration between structured reporting software, electronic medical records, accreditation bodies, and ImageGuide ${ }^{\mathrm{TM}}$. Such integration provides a constant quality improvement feedback loop for ever-improving report quality and patient care.

\section{Numeric Quantification of Perfusion Deficits}

It is evident from the work of Maddux et al. that improving adherence to defect quantification elements needs major work on the part of ASNC and accreditation agencies. It can be argued that the current defect quantification standards (small/medium/large, mild/moderate/severe, fixed/reversible) are perhaps "too crude." Outcome data in nuclear cardiology support numeric quantification of perfusion abnormality (summed stress score or total perfusion deficit) and ischemic burden (summed difference score or percent ischemic myocardium). ${ }^{9}$ Hachamovitch et al. demonstrated that patients with $>10 \%$ ischemic myocardium had better outcomes with coronary revascularization, while those with $<10 \%$ ischemic myocardium did better with medical therapy. ${ }^{9}$ Thus, reporting numeric quantification indices can further aid in dichotomous decision-making. We also have to consider whether future reporting standards should include prognostic statements and offer decision-making guidance. Integration of nuclear cardiology image analysis packages with structured reporting software can facilitate a seamless transfer of standardized quantitative and semiquantitative imaging data into the clinical report; decision support and machine learning tools can aid in generating patient-specific prognostic and decision guidance statements.

As we embark on the next leg of this journey, we have to ask ourselves: what do we want the nuclear cardiology report to achieve? We want to help our referring physicians with decision-making and improve our patients' outcomes. Toward these ends, the study by Maddux et al. suggests that our efforts appear to be bearing fruit. The cup is perhaps half-full. This is a call 
to action to leverage technology to fill in the remaining half and satisfy the thirst of the field for perfection.

\section{Disclosure}

Rami Doukky receives research funding from Astellas Pharma Global Development. Neha Yadav has no conflicts to report.

\section{References}

1. Maddux PT, Farrell MB, Ewing JA, Tilkemeier PL. Improved compliance with reporting standards: A retrospective analysis of intersocietal accreditation commission nuclear cardiology laboratories. J Nucl Cardiol. 2016. doi:10.1007/s12350-016-0713-y.

2. Hendel RC, Wackers FJ, Berman DS, Ficaro E, Depuey EG, Klein L, et al. American society of nuclear cardiology consensus statement: Reporting of radionuclide myocardial perfusion imaging studies. J Nucl Cardiol. 2003;10:705-8.

3. Hendel RC, Wackers FJ, Berman DS, Ficaro E, DePuey EG, Klein L, et al. American Society of Nuclear Cardiology consensus statement: Reporting of radionuclide myocardial perfusion imaging studies. J Nucl Cardiol. 2006;13:e152-6.

4. Douglas PS, Hendel RC, Cummings JE, Dent JM, Hodgson JM, Hoffmann U, et al. ACCF/ACR/AHA/ASE/ASNC/HRS/NASCI/ RSNA/SAIP/SCAI/SCCT/SCMR 2008 health policy statement on structured reporting in cardiovascular imaging. J Am Coll Cardiol. 2009;53:76-90.

5. Hendel RC, Budoff MJ, Cardella JF, Chambers CE, Dent JM, Fitzgerald DM, et al. ACC/AHA/ACR/ASE/ASNC/HRS/NASCI/ RSNA/SAIP/SCAI/SCCT/SCMR/SIR $2008 \mathrm{Key}$ data elements and definitions for cardiac imaging a report of the American College of Cardiology/American Heart Association Task Force on Clinical Data Standards (Writing Committee to Develop Clinical Data Standards for Cardiac Imaging). J Am Coll Cardiol. 2009:53:91-124

6. Tilkemeier PL, Cooke CD, Grossman GB, McCallister BD, Ward RP. Standardized reporting of radionuclide myocardial perfusion and function. J Nucl Cardiol. 2009;16:650.

7. Intersocietal Accreditation Commission. The IAC Standards and Guidelines for Nuclear/PET Accreditation 2016
8. Tilkemeier PL, Serber ER, Farrell MB. The nuclear cardiology report: Problems, predictors, and improvement. A report from the ICANL database. J Nucl Cardiol. 2011;18:858-68.

9. Hachamovitch R, Hayes SW, Friedman JD, Cohen I, Berman DS. Comparison of the short-term survival benefit associated with revascularization compared with medical therapy in patients with no prior coronary artery disease undergoing stress myocardial perfusion single photon emission computed tomography. Circulation. 2003;107:2900-7.

10. Shaw LJ, Berman DS, Maron DJ, Mancini GB, Hayes SW, Hartigan PM, et al. Optimal medical therapy with or without percutaneous coronary intervention to reduce ischemic burden: Results from the Clinical Outcomes Utilizing Revascularization and Aggressive Drug Evaluation (COURAGE) trial nuclear substudy. Circulation. 2008;117:1283-91.

11. Motwani M, Dey D, Berman DS, Germano G, Achenbach S, AlMallah $\mathrm{MH}$ et al. Machine learning for prediction of all-cause mortality in patients with suspected coronary artery disease: A 5year multicentre prospective registry analysis. Eur Heart J. 2016. doi:10.1093/eurheartj/ehw188.

12. Arsanjani R, Dey D, Khachatryan T, Shalev A, Hayes SW, Fish M, et al. Prediction of revascularization after myocardial perfusion SPECT by machine learning in a large population. J Nucl Cardiol. 2015;22:877-84.

13. Doukky R, Hayes K, Frogge N, Balakrishnan G, Dontaraju VS, Rangel MO, et al. Impact of appropriate use on the prognostic value of single-photon emission computed tomography myocardial perfusion imaging. Circulation. 2013;128:1634-43.

14. Doukky R, Frogge N, Appis A, Hayes K, Khoudary G, Fogg L, et al. Impact of appropriate use on the estimated radiation risk to men and women undergoing radionuclide myocardial perfusion imaging. J Nucl Med. 2016;57:1251-7.

15. Dos Santos MA, Santos MS, Tura BR, Felix R, Brito AS, De Lorenzo A. Budget impact of applying appropriateness criteria for myocardial perfusion scintigraphy: The perspective of a developing country. J Nucl Cardiol. 2016. doi:10.1007/s12350-016-0505-4.

16. Doukky R, Hayes K, Frogge N, Nazir NT, Collado FM, Williams KA. Impact of insurance carrier, prior authorization, and socioeconomic status on appropriate use of SPECT myocardial perfusion imaging in private community-based office practice. Clin Cardiol. 2015;38:267-73.

17. Tilkemeier PL, Mahmarian JJ, Wolinsky DG, Denton EA. ImageGuide update. J Nucl Cardiol. 2015;22:994-7. 